\title{
Effects of thermal treatment of activated carbon on the electrochemical behaviour in
}

\section{supercapacitors}

\author{
V. Ruiz, ${ }^{*}$ C. Blanco, E. Raymundo-Piñero ${ }^{\#}$, V. Khomenko ${ }^{\#}$, F. Béguin ${ }^{\#}$ and R. Santamaría \\ Instituto Nacional del Carbón (CSIC), Apdo. 73, 33080-Oviedo, Spain \\ ${ }^{\#}$ CRMD, CNRS-Université, $1 B$ rue de la Férollerie, 45071 Orléans Cedex 02, France
}

\begin{abstract}
This paper studies the electrochemical behaviour of activated carbons with different oxygen content and investigates the contribution of pseudocapacitance to the global behaviour of the samples. A mesophase-derived activated carbon was further heat treated to 600 or $1000^{\circ} \mathrm{C}$ in nitrogen. The changes in texture and surface chemistry induced by the thermal treatment were deeply studied. The electrochemical behaviour of the samples was studied in two- and three-electrode cells. The contribution of pseudocapacitance was evaluated by cyclic voltammetry and by the differences of specific capacitance obtained from galvanostatic tests performed in acidic $\left(\mathrm{H}_{2} \mathrm{SO}_{4}\right)$ and basic $(\mathrm{KOH})$ media. The presence of an extra capacitance due to redox reactions has been proved both in acidic and basic media for the samples with high oxygen content, although its contribution in basic media is significantly lower. The results obtained clearly indicate that the oxygen responsible for $\mathrm{CO}$-evolution participates in redox reactions, whereas the oxygen responsible for the $\mathrm{CO}_{2}$-evolution is of minor importance.
\end{abstract}

Keywords: activated carbon, supercapacitors, pseudocapacitance, surface chemistry, surface area.

\footnotetext{
* Corresponding autor: clara@incar.csic.es; Tel. + 349851190 90; Fax: + 34985297662
} 


\section{INTRODUCTION}

Supercapacitors have a significant potential as an alternative or complement to other energy storage or generation devices such as secondary batteries and fuel cells [1]. Carbon materials have been shown as the most attractive electrode materials for these supercapacitors, as a consequence of their relatively low cost, high surface area and availability [2]. In particular, activated carbons obtained by chemical activation of mesophase-derived precursors generally exhibit very good electrochemical performance in this application [3, 4]. In carbon based supercapacitors, energy is stored mainly through the formation of the electrical double layer, although part of the capacitance can be attributed to pseudo-faradaic reactions involving the oxygenated surface groups [5]. However, the surface chemistry of activated carbons is complex and rather different depending on the raw materials and activation conditions and not all the functional groups contribute to pseudocapacitance to the same extent [6-7]. Therefore, it is necessary to investigate the pseudocapacitative phenomena in order to optimise the performance of activated carbons as electrodes in supercapacitors [8-9].

This paper studies the electrochemical behaviour of activated carbons with different oxygen content and investigates the contribution of pseudocapacitance to the global behaviour of the samples. Therefore, a mesophase-derived activated carbon was treated to 600 or $1000^{\circ} \mathrm{C}$ and the changes in texture and surface chemistry induced by the thermal treatment were deeply studied. The electrochemical behaviour of the samples was studied in two- and threeelectrode cells in acidic $\left(\mathrm{H}_{2} \mathrm{SO}_{4}\right)$ and basic $(\mathrm{KOH})$ media.

\section{EXPERIMENTAL}

\section{Activated Carbons}


The naphthalene derived mesophase pitch AR24 was chemically activated using (3:1) KOH to carbon mass ratio, at $700^{\circ} \mathrm{C}$ for one hour, under a nitrogen flow of $62 \mathrm{~mL} \mathrm{~min}{ }^{-1}$. The resultant material was neutralized with $1 \mathrm{M} \mathrm{HCl}$ and then washed with distilled water until $\mathrm{pH}=7$. Finally, the carbon was dried at $110^{\circ} \mathrm{C}$ in a vacuum oven for $24 \mathrm{~h}$. The resultant activated carbon was labelled $\mathrm{AC}$ and was then thermally treated at 600 and $1000^{\circ} \mathrm{C}$ in a horizontal furnace under a nitrogen flow of $65 \mathrm{~mL} \mathrm{~s}^{-1}$. The resultant samples were labelled AC-600 and AC-1000, respectively.

\section{Characterisation of Activated Carbons}

Physical adsorption of $\mathrm{N}_{2}$ at $77 \mathrm{~K}$ and $\mathrm{CO}_{2}$ at $273 \mathrm{~K}$ was carried out in order to characterise the porous texture of the activated carbons and carbon electrodes. The specific surface area was determined from the $\mathrm{N}_{2}$ adsorption isotherm using the BET equation. The micropore volume was calculated from the application of the Dubinin-Radushkevich (DR) equation either to the $\mathrm{N}_{2}$ isotherm $\left(\mathrm{V}_{\mathrm{N} 2}\right)$ or to the $\mathrm{CO}_{2}$ isotherm $\left(\mathrm{V}_{\mathrm{CO} 2}\right)$. The total pore volume was obtained from the $\mathrm{N}_{2}$ adsorption at $\mathrm{P} / \mathrm{P}_{0}=0.99$. The volume of mesopores was calculated by subtracting the total micropore volume $\left(\mathrm{V}_{\mathrm{N} 2}\right)$ from the total pore volume.

The oxygen content of the activated carbons was determined by elemental analysis using a LECO-TF-900 furnace coupled to a LECO-CHNS-932 microanalyser. The surface oxygen functionality was studied by X-ray photoelectron spectroscopy (XPS) using a VG-Microtech Multilab 3000 spectrometer equipped with a hemispherical electron analyser and a $\mathrm{Mg} \mathrm{K}_{\alpha}(h v$ $=1253.6 \mathrm{eV}) \mathrm{X}$-ray source.

The amount and type of oxygenated surface groups were determined by temperatureprogrammed decomposition (TPD) under inert atmosphere (He). The sample (150 mg) was 
placed in a U-shaped quartz cell and treated at $372 \mathrm{~K}$ for $1 \mathrm{~h}$ under a He flow of $50 \mathrm{ml} / \mathrm{min}$. Then, the temperature was raised at $10^{\circ} \mathrm{C} / \mathrm{min}$ to $1000^{\circ} \mathrm{C}$. On-line mass spectrometry was used to measure the decomposition products $\left(\mathrm{CO}\right.$ and $\left.\mathrm{CO}_{2}\right)$.

The $\mathrm{pH}$ of the activated carbons was determined according to the ASTM D3838-80. The samples were boiled in water using a reflux condenser for $900 \mathrm{~s}$. Then the carbon particles were filtered out and the $\mathrm{pH}$ of the filtrate measured after cooling down.

\section{Electrochemical Behaviour}

The electrochemical performance of the activated carbons was studied on pellet type electrodes prepared by pressing a mixture of activated carbon (90 wt. \%) and PVDF (10 wt. \%). The mass of each electrode was about $30 \mathrm{mg}$. Two-electrode capacitors were built with a glassy fibrous separator and gold current collectors, using a Teflon Swagelok® type system. Tests were performed in $1 \mathrm{M} \mathrm{H}_{2} \mathrm{SO}_{4}$ and $6 \mathrm{M} \mathrm{KOH}$. The values of capacitance were estimated from galvanostatic charge/discharge cycling in the voltage range between 0 and $0.8 \mathrm{~V}$ at

current densities from 0.88 to $88 \mathrm{~mA} / \mathrm{cm}^{2}$ using a VMP (Biologic, France) multichannel generator. These values were expressed by mass of activated carbon in the smallest electrode. Voltammetry experiments (scan rate of potential from 2 to $10 \mathrm{mV} / \mathrm{s}$ ) were done in two and three-electrode cells. In the three-electrode configuration, Pt was used as auxiliary electrode and $\mathrm{Hg} / \mathrm{Hg}_{2} \mathrm{SO}_{4}$ or $\mathrm{Hg} / \mathrm{HgO}$ as reference electrodes and the values of potential are reported versus the normal hydrogen electrode (NHE).

\section{RESULTS AND DISCUSSION}

\section{Activated Carbons}


The activated carbon $\mathrm{AC}$ obtained after chemical activation with $\mathrm{KOH}$ is highly microporous, as indicated by the volume of adsorbed nitrogen and the shape of the isotherm (Type I) shown in Figure 1. The textural parameters obtained from the isotherm are summarised in Table 1. The total pore volume of this carbon is $0.85 \mathrm{~cm}^{3} / \mathrm{g}$, most of the pores being micropores $(88 \%)$, with an average pore diameter of $0.97 \mathrm{~nm}$. The micropore volume estimated from the $\mathrm{CO}_{2}$ isotherms is significantly lower than that obtained from the $\mathrm{N}_{2}$ ones, this indicating that the contribution of narrow micropores is negligible. The contribution of mesopores to this sample is rather insignificant $\left(0.10 \mathrm{~cm}^{3} / \mathrm{g}\right)$. The microporous surface area and the BET surface area are both very high, as a result of the high volume of micropores present in the sample.

When the activated carbon is treated at $600^{\circ} \mathrm{C}$, the total pore volume decreases slightly (Table 1 and Figure 1), the type of porosity remaining essentially the same as for the activated carbon AC. However, when the heat treatment temperature is increased up to $1000^{\circ} \mathrm{C}$, the texture of the activated carbon changes more significantly. The decrease of total pore volume and average micropore size is the result of the textural reorganization which occurs during the treatment at higher temperatures.

The data given by elemental analysis, XPS, TPD reveal that the amount of oxygen present in the samples decreases very significantly from AC to AC-600 and AC-1000 (Table 2). The higher values measured by XPS in comparison to elemental analysis indicate that oxygen is mainly located at the surface of carbons. The reduction of the oxygen content caused a significant increase of $\mathrm{pH}$, which varied from 2.8 for AC to 7.3 for AC-1000, suggesting that AC contains carboxylic groups, which are removed after heat treatment up to $1000^{\circ} \mathrm{C}$. This is in agreement with the results given by TPD experiments (Table 2). Figure 2 shows the TPD 
profiles obtained for the samples, showing the evolution of $\mathrm{CO}_{2}$ and $\mathrm{CO}$. Upon heating carbon materials, $\mathrm{CO}_{2}$ evolves at low temperature as a consequence of decomposition of carboxylic groups, lactones or anhydrides [10]. CO evolution occurs at higher temperatures, due to the decomposition of basic or neutral groups such as phenols, ethers and carbonyl groups. For the three activated carbons under study, $\mathrm{CO}$ evolved in larger amounts than $\mathrm{CO}_{2}$. As could be expected when the activated carbon was heat treated at only $600^{\circ} \mathrm{C}$, most of the acidic groups were removed, whereas the groups responsible for the $\mathrm{CO}$ evolution are still present. After the treatment at $1000^{\circ} \mathrm{C}$ most of the oxygenated functional groups are removed.

\section{Electrochemical Characteristics}

$\mathrm{H}_{2} \mathrm{SO}_{4}$ as electrolyte

Figure 3 shows an example of the charge-discharge curves obtained for the different samples at $1 \mathrm{~mA}$ and that were used to calculate the specific capacitance of the samples. The coulombic efficiency was high for all the samples studied (higher than $99 \%$ ). Figure 4 shows the influence of current density on the specific capacitance values determined for the three carbons using a two-electrode cell in $\mathrm{H}_{2} \mathrm{SO}_{4}$ medium. As could be expected, the sample $\mathrm{AC}$, with the highest pore volume and surface area, demonstrates the highest specific capacitance. Thermal treatment provokes a reduction of capacitance, which is quite important for the sample treated at $1000^{\circ} \mathrm{C}$. The decrease of capacitance is significantly larger than it could be expected from the variations of specific surface area/pore volume induced by heat treatment of the samples. Therefore, it is reasonable to assign these changes to the modification of oxygenated surface functionality. It is well known that the presence of oxygenated groups may cause the capacitance to arise from quick Faradaic charge transfer reactions (pseudocapacitance) as well as from electrostatic charging [5]. Hence, some calculations have been made in order to estimate the contribution of pseudocapacitance to the 
electrochemical performance of the samples under study. These calculations are just an approximation, as only changes in texture and pseudocapacitance are being considered. Other factors, such as wettability and conductivity, which also influence the total capacitance and are certainly modified by the thermal treatment, were not taken into account.

The decrease of capacitance observed from AC to AC-600 (Figure 4) is proportional to the reduction of microporous surface area (Smic), estimated to $8 \%$. Then, it can be assessed that the oxygen removed at $600^{\circ} \mathrm{C}$, which corresponds to $\mathrm{CO}_{2}$-evolving groups, does not contribute to capacitance. On the contrary, the specific capacitance of AC-1000 is $36 \%$ lower than for AC, whereas the microporous surface area is only $14 \%$ lower. This mismatch can be related to the removal of CO-desorbing complexes, and consequently to the pseudofaradaic reactions which are associated to their presence [7]. Hence, pseudocapacitance significantly contributes $(\sim 22 \%)$ to the total capacitance of the samples AC in this medium.

The voltammograms obtained in two-electrode cells (Figure 5-a) did not show evidence of pseudocapacitance. On the contrary, pseudocapacitance was clearly observed when cyclic voltammetry was performed in the three-electrode configuration (Figure 5-b). Well-defined redox humps are shown by the AC-electrode. These peaks are significantly smaller for AC600 and almost negligible for AC-1000. These results are in agreement with the results discussed above in relation to the role of the $\mathrm{CO}$ evolving groups (carbonyl or quinone- type groups) in the enhancement of capacitance. Moreover, the voltammograms show that the redox reactions occur both in the anodic and cathodic regions which means that this pseudocapacitance is readily used in a symmetric supercapacitor.

KOH as electrolyte 
The electrochemical characteristics of the samples were also studied in basic medium (KOH 6M) (Figure 6 and 7). The specific capacitance of sample AC was slightly higher than that of AC-600, and significantly higher than that of AC-1000 (Figure 6), a similar trend to that observed in sulphuric medium, although, the values of the first two samples are lower in $\mathrm{KOH}$ (about 16-18\% lower). According to the voltammograms obtained in the threeelectrode configuration (Figure 7-b), the specific capacitance is comparable to the values obtained in sulfuric acid. However, in the alkaline medium the redox reaction of surface groups shifts to negative potentials. In the two-electrode configuration, the capacitance of the whole device is limited by the electrode with the lowest performance, which is the positive one, as can be seen in Figure 7-b. This explains the lower capacitance values obtained in $\mathrm{KOH}$ than in $\mathrm{H}_{2} \mathrm{SO}_{4}$.

Similar calculations to those discussed before for sulfuric medium were done for results obtained in $\mathrm{KOH}$ (Figure 6) in order to evaluate the contribution of pseudocapacitance. The decrease in capacitance from $\mathrm{AC}$ to $\mathrm{AC}-600$ is around $8 \%$ and, therefore, proportional to the reduction of microporous surface area (similar to that observed in sulphuric medium). Meanwhile, the decrease in capacitance observed for AC-1000 is larger than the reduction in microporous surface area $(25 \%$ vs. $14 \%)$. Therefore, it can be estimated that in $\mathrm{KOH}$ media about $11 \%$ of the total capacitance of sample AC is due to pseudocapacitance, giving a clear evidence of the presence of pseudocapacitance also in $\mathrm{KOH}$ medium for samples $\mathrm{AC}$ and AC-600. However, its contribution to the total capacitance is less than in sulphuric medium. The presence of pseudocapacitive phenomena in basic media is not so frequently described in the literature as in acidic media. Zuleta et al. [9] have suggested a reversible redox system involving phenol or quinone groups as responsible for the enhancement of the total capacitance. 


\section{CONCLUSIONS}

The thermal treatment of the mesophase-derived activated carbon at $600^{\circ} \mathrm{C}$ caused slight changes in texture accompanied by a significant reduction of oxygen content, mainly corresponding to $\mathrm{CO}_{2}$-evolving groups. The capacitance values of $\mathrm{AC}$ and $\mathrm{AC}-600$ are in accordance to the textural differences but are not affected by the modifications of the surface functionality. When the sample is further heat treated to $1000^{\circ} \mathrm{C}$, the capacitance values are significantly lower, not only due to the decrease of specific surface area but also to the removal of CO-evolving groups, responsible for pseudo-faradaic charge transfer reactions. The existence of an extra capacitance due to redox reactions has been proved both in acidic and in basic media for samples with high oxygen content. However, in basic media, part of the possible capacitance of the material is misused in a symmetric configuration. The contribution of pseudocapacitance in the two-electrode system has been estimated in about 22 $\%$ in acidic media and $11 \%$ in basic media.

\section{Acknowledgements}

This work has been performed with financial support from MEC (project MAT2004-03480C02) and FICYT (project IB05-086-C1). V. Ruiz acknowledges a predoctoral research grant from FICYT. The authors would like to thank University of Alicante for the XPS analyses. 


\section{References}

[1] R Kötz, M. Carlen, Electrochim. Acta 45 (2000) 2483-2498.

[2] E. Frackowiak, F. Béguin, Carbon 39 (2001) 937-950.

[3] K. Kierzek, E. Frackowiak, G. Lota, G. Gryglewicz, J. Machnikowski, Electrochim. Acta 49 (2004) 515-523.

[4] A. Alonso, V. Ruiz, C. Blanco, R. Santamaría, M. Granda, R. Menéndez, S.G.E. De Jager, Carbon 44 (2006), 441-446.

[5] B.E. Conway, in: Electrochemical capacitors: Scientific fundamentals and technological applications, Kluwer Academic, New York, 1999.

[6] M.J. Bleda-Martínez, J.A. Maciá-Agulló, D. Lozano-Castelló, E. Morallón, D. Cazorla-Amorós, A. Linares-Solano, Carbon 43 (2005), 2677-2684.

[7] Y.-R. Nian, H. Teng, J. Electrochem. Soc. 149 (2002), A1008-A1014.

[8] E. Frackowiak, G. Lota, J. Machnikowski, C. Vix-Guterl, F. Béguin, Electrochim. Acta, 51 (2006), 2209-2214.

[9] M. Zuleta, P. Björnbom, A. Lundblad, J. Electrochem. Soc., 152 (2005), A270-A276.

[10] G. Tremblay, F.J. Vastola, P.L. Walker, Carbon 16 (1978), 35-39. 
TABLE CAPTIONS

Table 1.- Textural characterisation of activated carbons

Table 2.- Physicochemical characterisation of the activated carbons. 
TABLE 1: Textural characterisation of activated carbons.

\begin{tabular}{ccccccccc}
\hline Sample & $\mathrm{V}_{\mathrm{T}}$ & $\mathrm{V}_{\mathrm{N} 2}$ & $\mathrm{~V}_{\mathrm{CO} 2}$ & $\mathrm{~V}_{\text {meso }}$ & $\mathrm{L}_{0}$ & $\mathrm{~S}_{\text {mic }}$ & $\mathrm{S}_{\mathrm{BET}}$ & \% micro \\
\hline AC & 0.85 & 0.75 & 0.58 & 0.10 & 0.97 & 1531 & 2008 & 88 \\
AC-600 & 0.80 & 0.70 & 0.52 & 0.10 & 1.00 & 1407 & 1884 & 87 \\
AC-1000 & 0.66 & 0.60 & 0.51 & 0.06 & 0.91 & 1318 & 1605 & 91 \\
\hline
\end{tabular}

$\mathrm{V}_{\mathrm{T}}$, total pore volume $\left(\mathrm{cm}^{3} / \mathrm{g}\right)$

$\mathrm{V}_{\mathrm{N} 2}$, total micropore volume $\left(\mathrm{cm}^{3} / \mathrm{g}\right)$

$\mathrm{V}_{\mathrm{CO} 2}$, micropore volume $\left(\mathrm{cm}^{3} / \mathrm{g}\right)$

$\mathrm{V}_{\text {meso }}$, mesopore volume $\left(\mathrm{cm}^{3} / \mathrm{g}\right)$
$\mathrm{L}_{0}$, average pore diameter $(\mathrm{nm})$

$\mathrm{S}_{\text {mic }}$, microporous surface $\left(\mathrm{m}^{2} / \mathrm{g}\right)$

$\mathrm{S}_{\mathrm{BET}}$, BET surface area $\left(\mathrm{m}^{2} / \mathrm{g}\right)$

$\%$ micro, microporosity percentage 
TABLE 2: Physicochemical characterisation of the activated carbons.

\begin{tabular}{lccccc}
\hline \multirow{2}{*}{ Sample } & O (wt \%) & O (\%) XPS & $\mathrm{pH}$ & \multicolumn{2}{c}{$\mathrm{TPD}$} \\
\cline { 5 - 6 } & & & & $\mathrm{CO}(\mathrm{mmol} / \mathrm{g})$ & $\mathrm{CO}_{2}(\mathrm{mmol} / \mathrm{g})$ \\
\hline $\mathrm{AC}$ & 3.54 & 8.12 & 2.8 & 1.223 & 0.225 \\
$\mathrm{AC}-600$ & 1.51 & 5.50 & 5.5 & 1.124 & 0.096 \\
AC-1000 & 0.33 & 2.48 & 7.3 & 0.134 & 0.080 \\
\hline
\end{tabular}

FIGURE CAPTIONS

Figure 1.- $\mathrm{N}_{2}$ adsorption/desorption isotherms of activated carbons.

Figure 2.- TPD profiles of activated carbons: a) $\mathrm{CO}_{2}$ evolution and b) $\mathrm{CO}$ evolution.

Figure 3.- Charge and discharge profiles of samples at $1 \mathrm{~mA}$.

Figure 4.- Variation of specific discharge capacitance with current density in $1 \mathrm{M}_{2} \mathrm{SO}_{4}$. Voltage window $=0.8 \mathrm{~V}$.

Figure 5.- Cyclic voltammetry performed at $2 \mathrm{mV} / \mathrm{s}$ in a) two-electrode and b) threeelectrode cell using $\mathrm{H}_{2} \mathrm{SO}_{4} 1 \mathrm{M}$ as electrolyte.

Figure 6.- Variation of specific discharge capacitance with current density in $6 \mathrm{M} \mathrm{KOH}$. Voltage window $=0.8 \mathrm{~V}$.

Figure 7.- Cyclic voltammetry performed at $2 \mathrm{mV} / \mathrm{s}$ in a) two-electrode and b) three-electrode cell using $6 \mathrm{M} \mathrm{KOH}$ as electrolyte. 


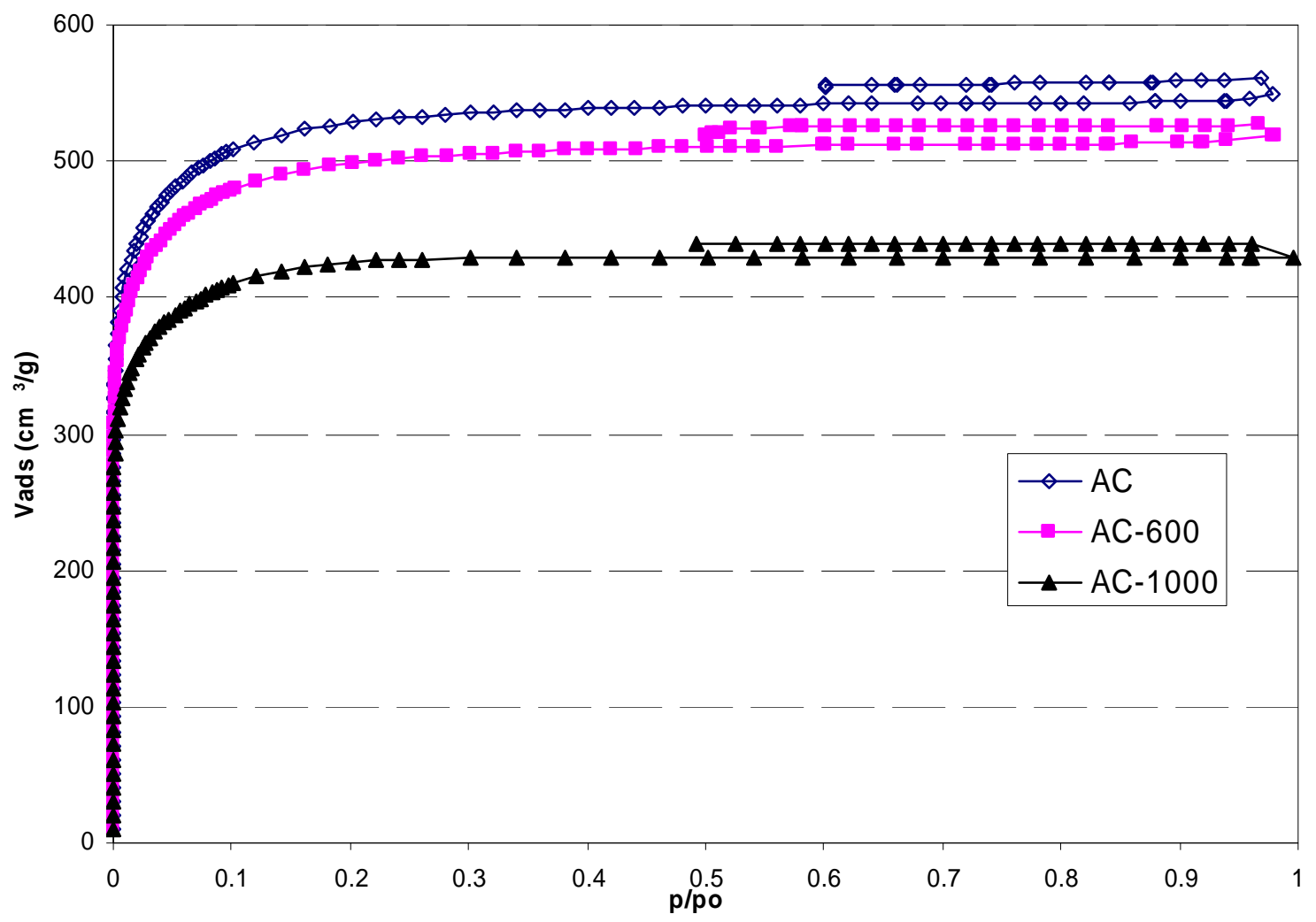

Figure 1 
a)

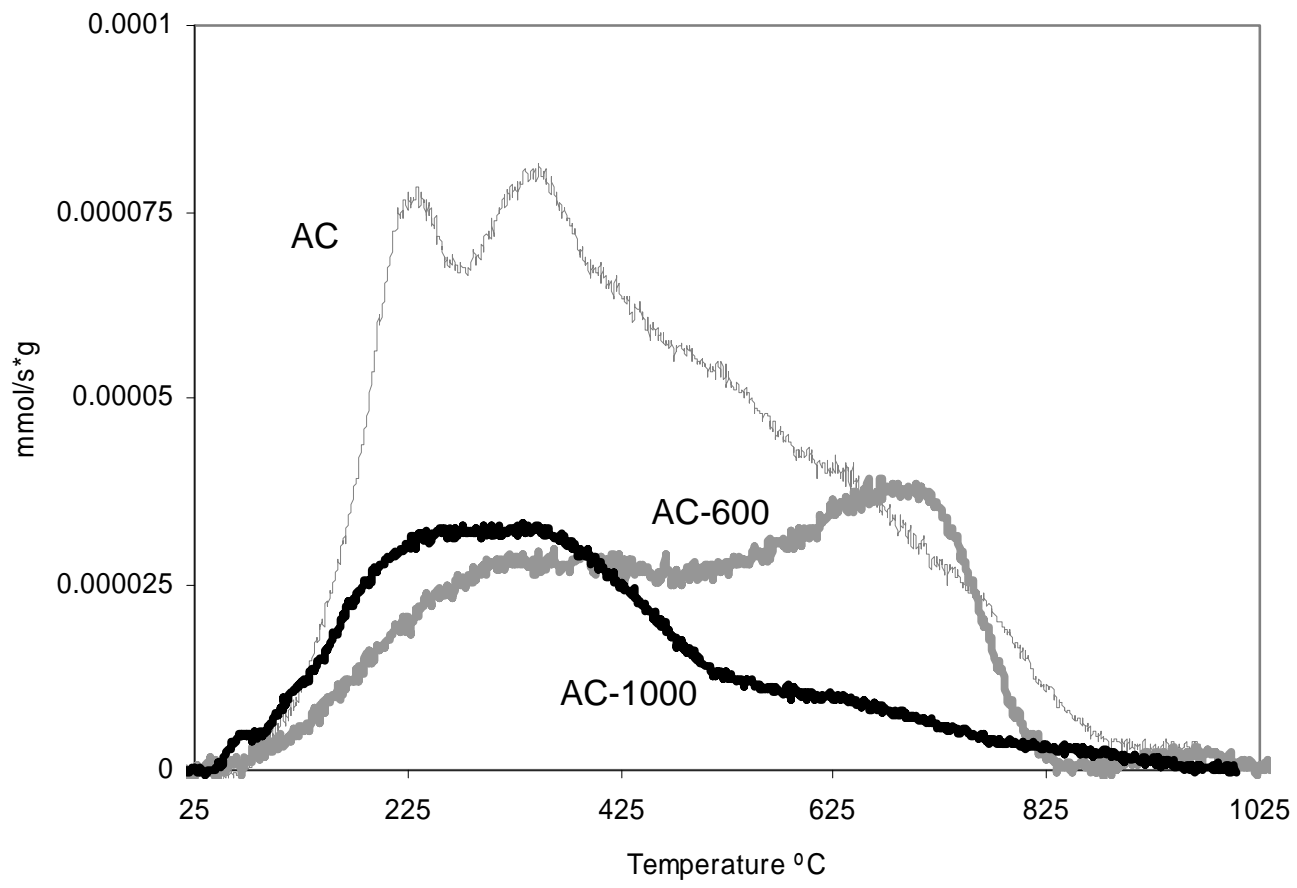

b)

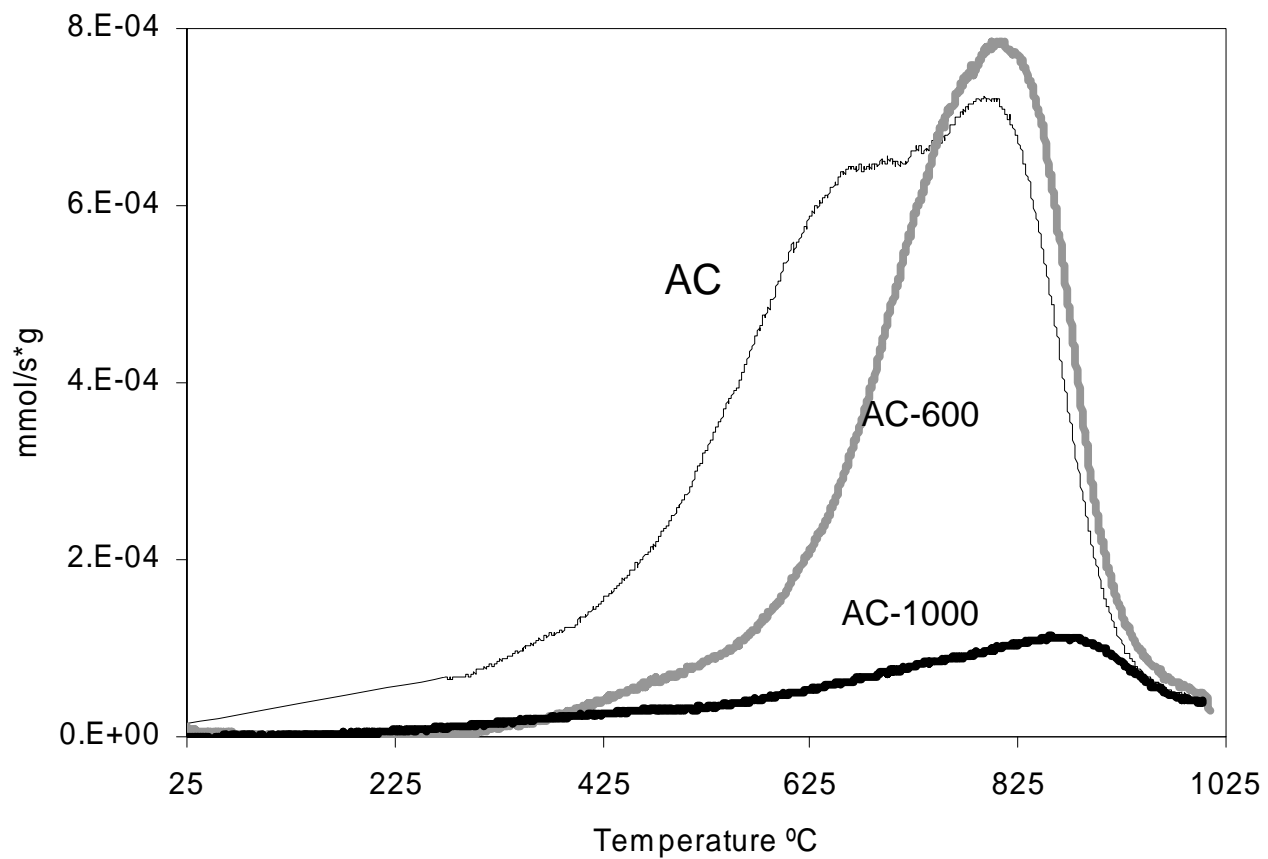

Figure 2 


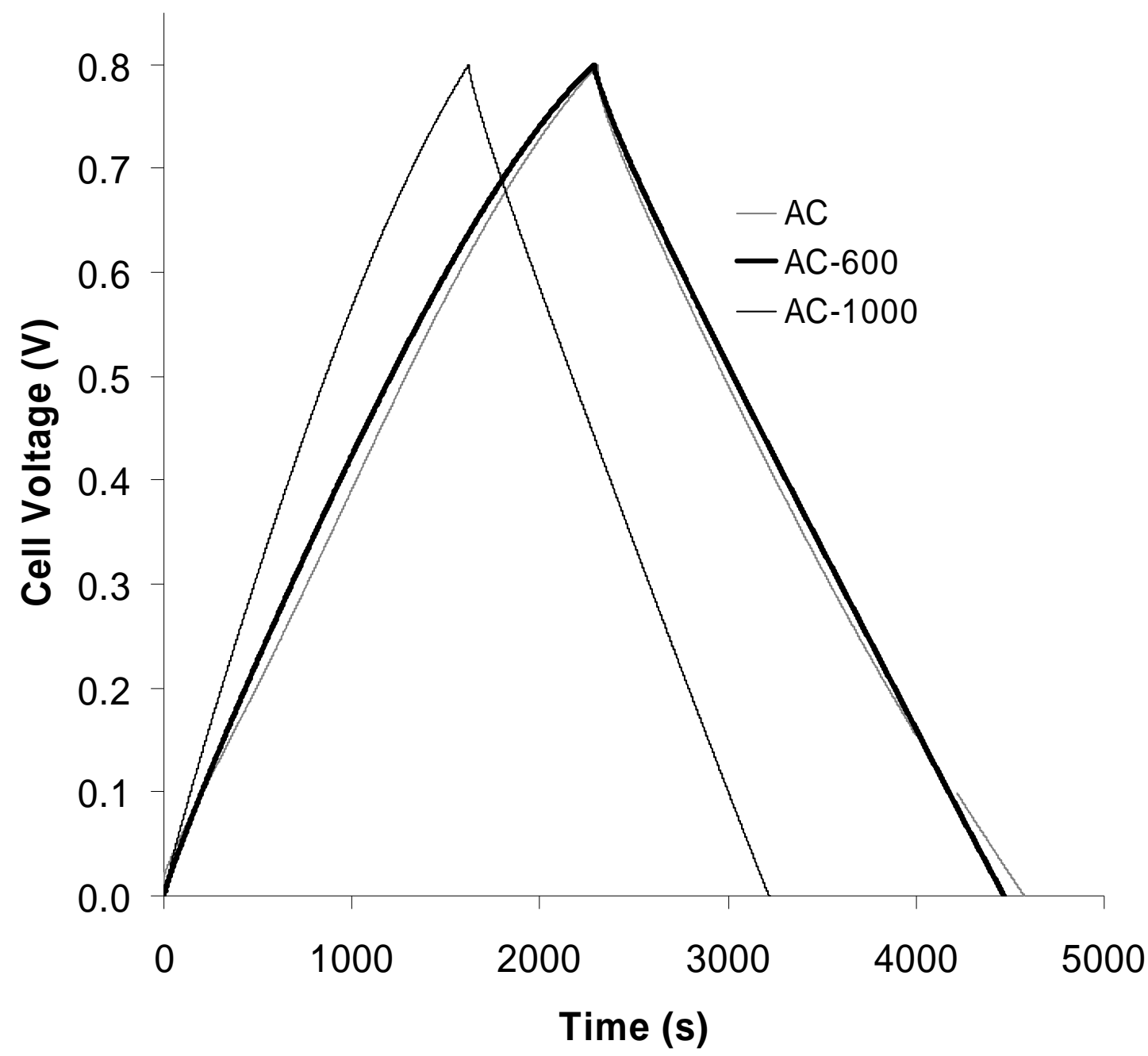

Figure 3 


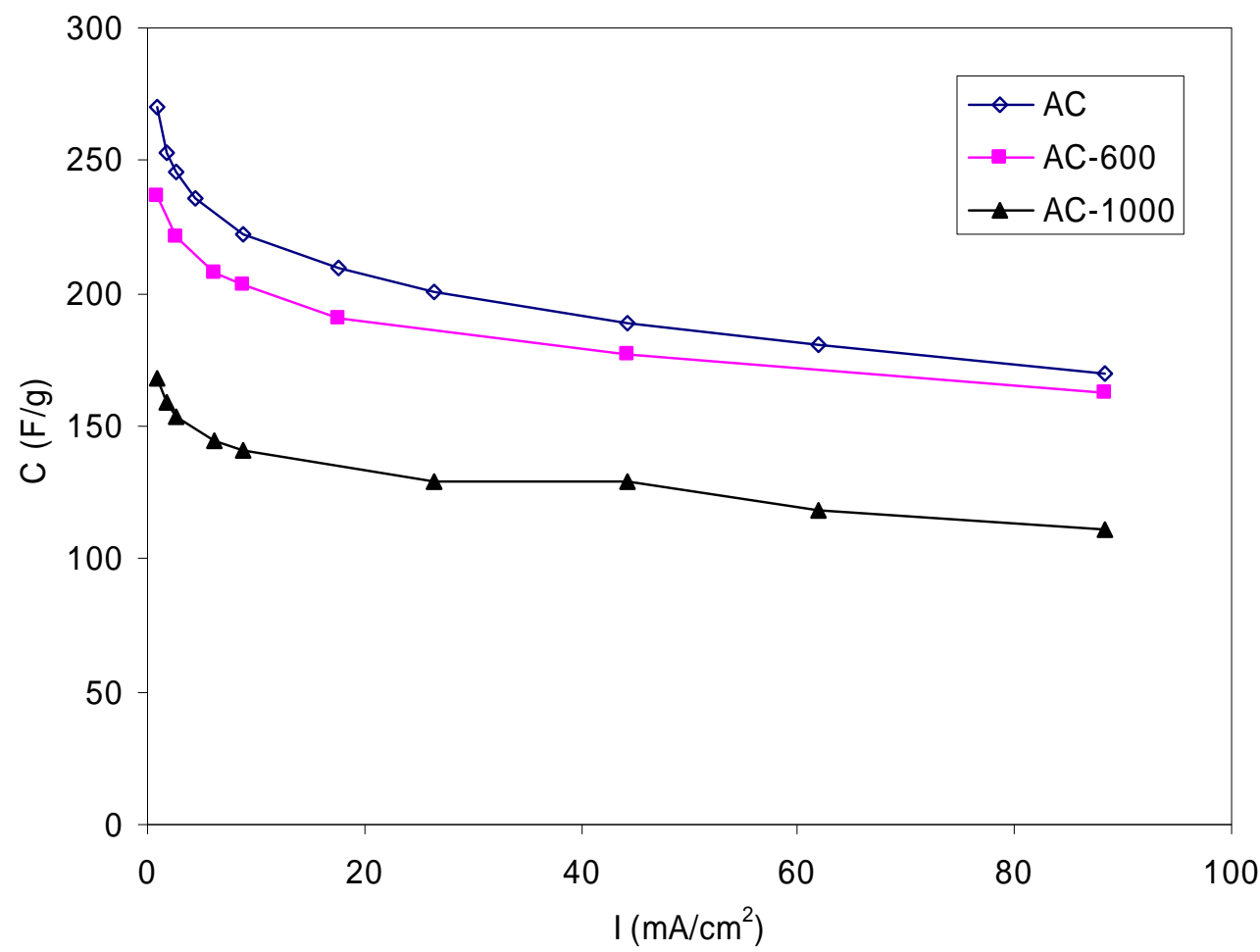

Figure 4 
a)

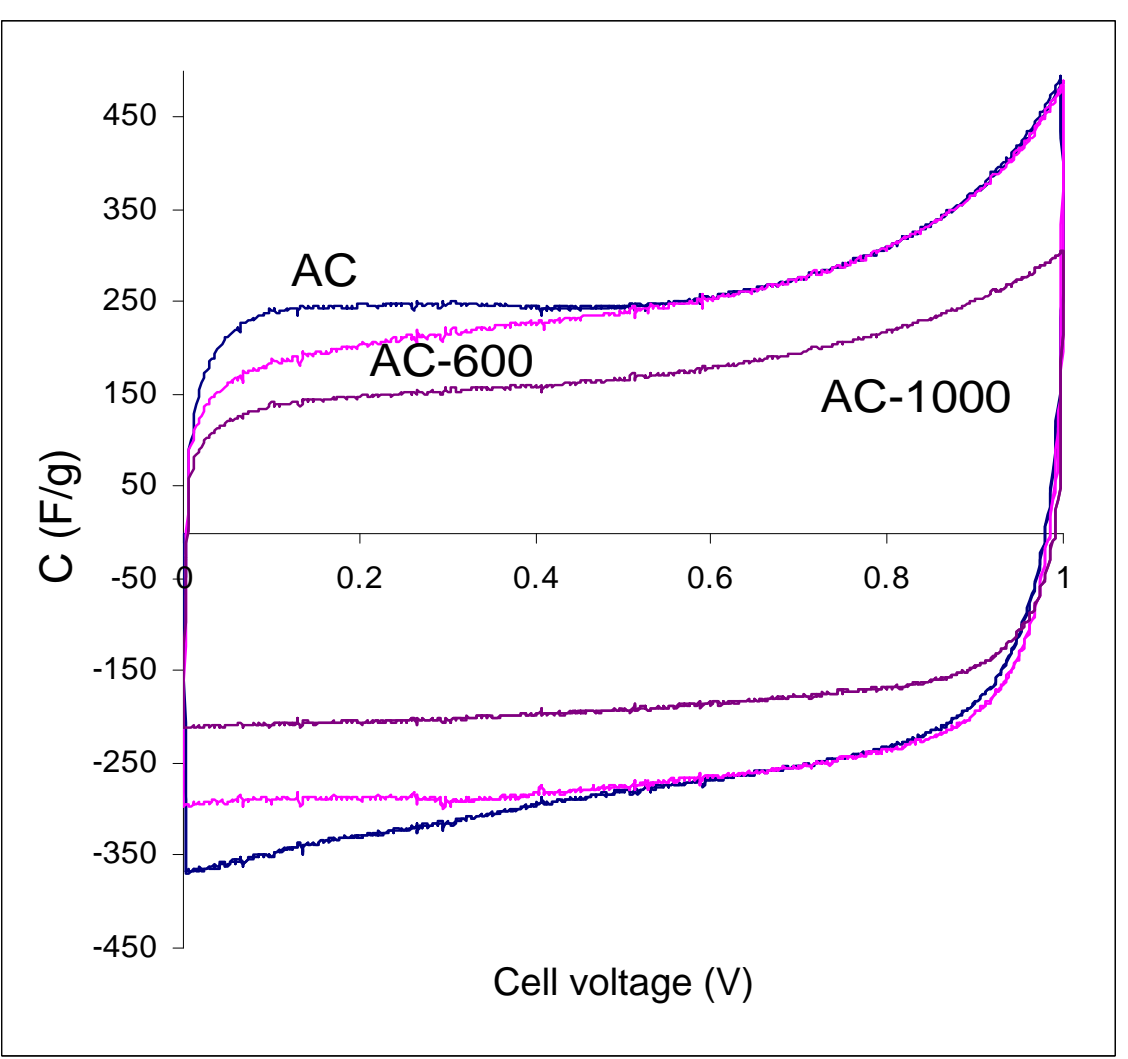

b)

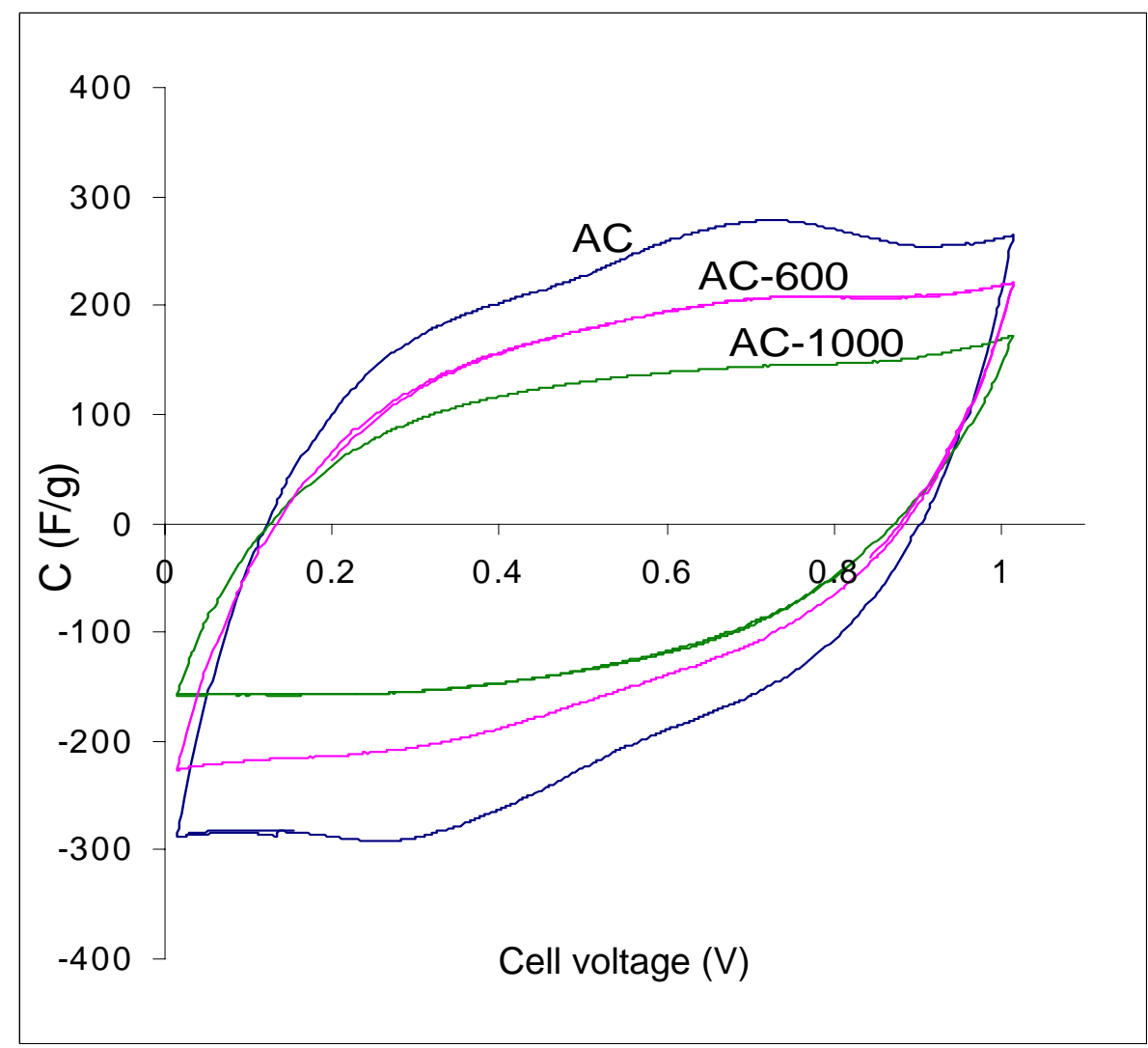

Figure 5 


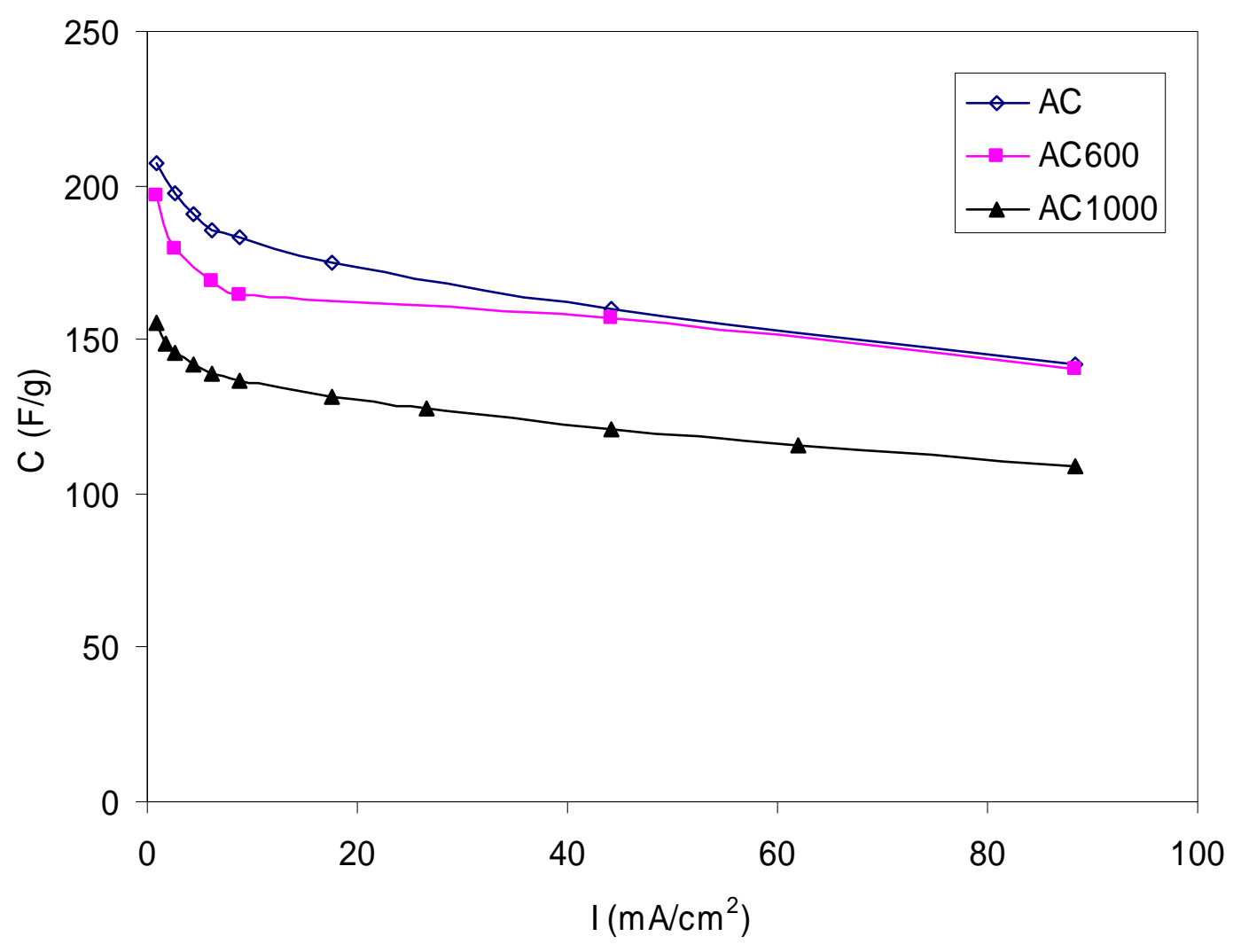

Figure 6.- 
a)

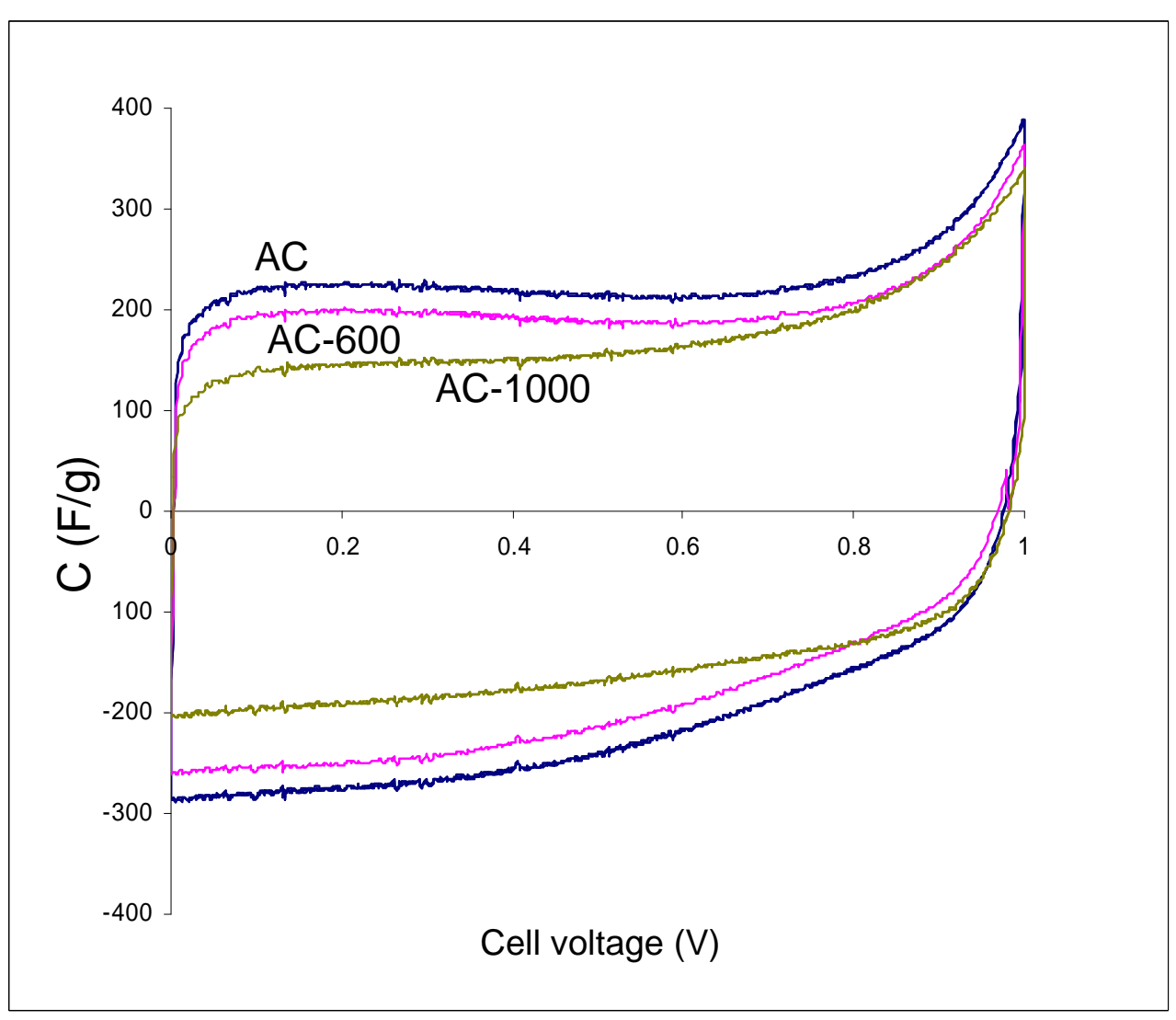

b)

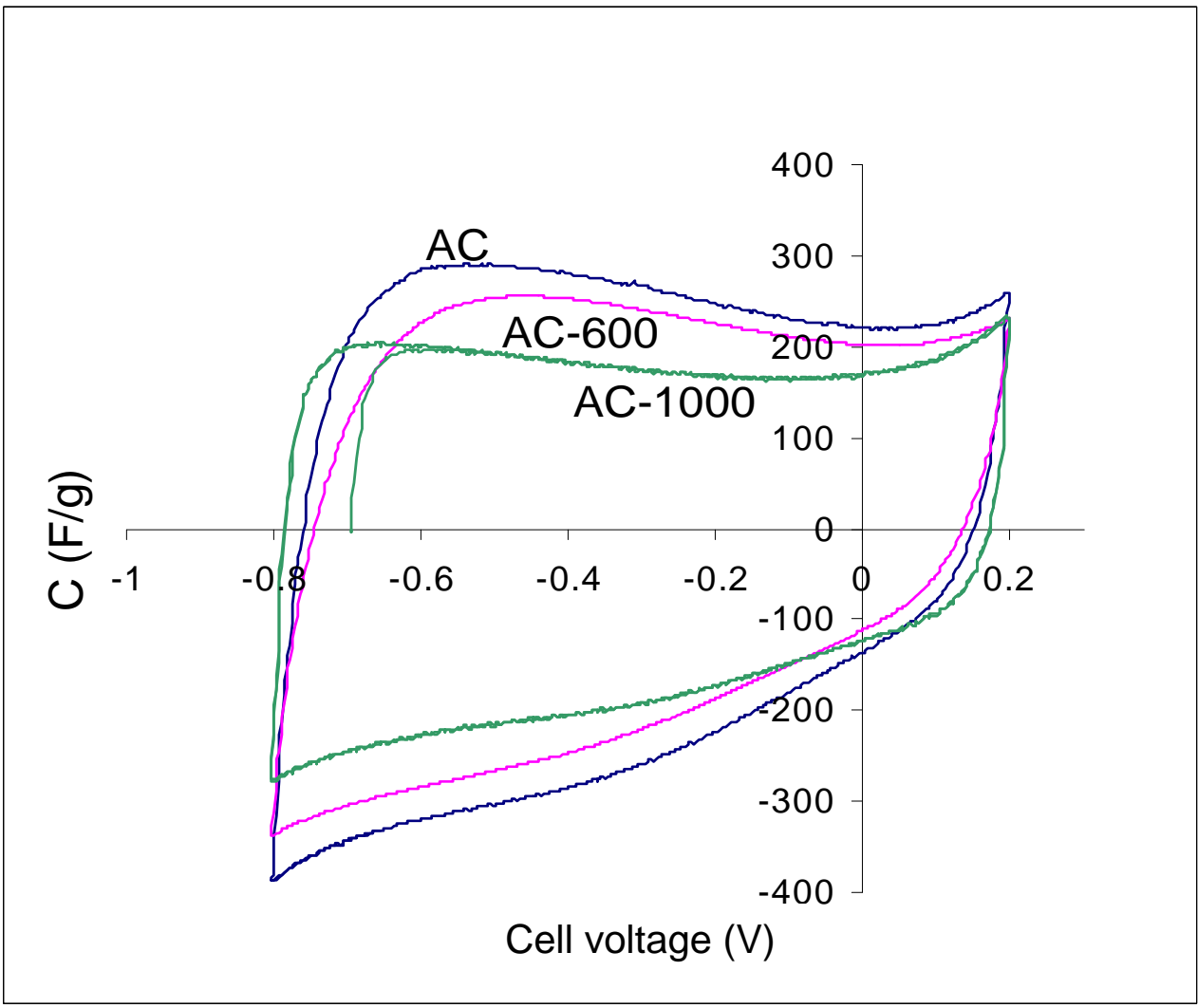

Figure 7.- 